Las modificaciones a la regulación ambiental minera y su impacto

Francisco Tong González

En el presente artículo, el autor realiza un análisis sobre las modificaciones a la regulación minera y el impacto que tienen en el ámbito social, llegando a concluir que para lograr el impulso de proyectos de inversión, se debe aumentar la claridad de las normas, suprimiendo procedimientos y trámites innecesarios, reduciendo plazos y sustituyendo la autorización administrativa por la comunicación previa. 


\section{Las modificaciones a la regulación ambiental minera y su impacto}

\section{Introducción}

De acuerdo al índex de libertad económica del 2015, realizado por la Fundación Heritage, el puntaje de libertad económica del Perú es de 67.7, es decir, 0.3 puntos mejor que el año pasado. Esto nos posiciona en el puesto 47 de 165 países del mundo y puesto 8 dentro de Latinoamérica. La razón de este cambio, según dicha fundación, se debe a la reducción de la corrupción (aunque mínima), así como a la apertura de las libertades laborales y monetarias. Sin embargo, la evaluación es negativa en cuanto a la libertad de empresa, gestión del gasto público y libertad fiscal. Aun así, según la opinión de la fundación, las reformas normativas y la industria minera han facilitado un rápido crecimiento económico ${ }^{1}$. No obstante, y como veremos más adelante, este crecimiento podría ser aún mayor a pesar del periodo internacional de crisis en el que nos encontramos.

En la última década la inversión en el sector minero ha pasado de 1,086 millones de dólares a 9,723 millones de dólares en el año 2013 y alrededor de 8,643 millones de dólares en el 2014 a pesar del declive que viene sufriendo la industria minera internacional ${ }^{2}$. Sin embargo, del análisis de los datos recogidos en la encuesta realizada por el Instituto Fraser en el período 2012 - 2013, se concluyó lo siguiente:

“El índice de potencial minero sin regulación, ubica al Perú en el $35^{\circ}$ lugar de 96 países encuestados. Cabe señalar que la percepción respecto de nuestro potencial empeoró en el último año [refiriéndose al año 2013]. En el caso de potencial minero bajo la regulación actual, descendemos al puesto $38^{\circ}$.

Si observamos el índice de potencial de políticas veremos que también se disminuye, dado que los inversionistas tienen una percepción negativa del mismo ya que nos ubican en el $50 \%$ inferior de la muestra de países (puesto 58), muy por debajo de nuestros principales competidores (Québec, Nevada, Chile, entre otros).

Finalmente, en el resultado global (el índice compuesto de potencial minero y potencial de políticas) coloca al país en la posición 40 , lo que nos dice que las políticas implementadas en nuestro país afectan de forma

$1 \quad$ Freedom Economic Index 2015. www.heritage.org/index/country/peru.

2 Estadística. Sociedad de Minería y Petróleo.

http://www.estadisticassnmpe.org.pe/EstExt_Principal/EstExt_Pri_Menu.aspx?x=5441791 $\underline{\text { \&parCodl ndicador }=21 \& \text { parCodRubro }=2}$ 
considerable el interés de los inversionistas por invertir en nuestro país" ${ }^{3}$.

(El énfasis es propio).

Por lo tanto, tener una vasta riqueza en recursos naturales, principalmente minerales y una tradición minera, no es requisito suficiente para atraer mayores inversiones. Queda claro entonces que el desarrollo de la mencionada actividad y la promoción de inversiones requieren contar con un marco normativo de características tales que otorguen al inversionista, la seguridad y estabilidad suficiente para poner en marcha un proyecto de largo aliento y ardua espera.

Esta idea se acentúa si tomamos en consideración los niveles de competitividad alcanzados por el Perú a nivel mundial. De acuerdo al Reporte Global de Competitividad 2014- 2015, elaborado por el Forum del Banco Mundial, el Perú habría descendido cuatro posiciones encontrándose en el puesto 65 de 144 países. Importa remarcar que, en opinión de la mencionada institución, el factor más problemático para hacer negocios viene a ser la burocracia gubernamental ineficiente (puesto 118), seguido por la corrupción (puesto 103). Así, el mencionado reporte concluye lo siguiente:

A pesar de la caída del Perú de cuatro posiciones hasta el lugar número 65, el país continúa estando posicionado dentro de la mitad superior de la clasificación. Preocupaciones sobre el funcionamiento de su Institución $\left(118^{\circ}\right)$, junto con el progreso insuficiente en la mejora de la calidad de su educación $\left(134^{\circ}\right)$ y adaptación de nuevas tecnologías $\left(92^{\circ}\right)$, explican este descenso, apoyando la idea resaltada el año pasado [2013], de un cierto agotamiento de las fuentes de ganancias de competitividad del país en el último año. Entre estos logros esta una muy fuerte actuación a nivel macroeconómico $\left(21^{\circ}\right)$ y altos niveles de eficiencia en los mercados de bienes $\left(53^{\circ}\right)$, de finanzas $\left(40^{\circ}\right)$, y el mercado laboral $\left(51^{\circ}\right)$ a pesar de la rigidez en las prácticas de contratación y despido $\left(130^{\circ}\right)$. Aunque el Perú se ha beneficiado recientemente de fuertes crecimiento gracias a la subida del precio de los minerales, el país debe construir su resiliencia dirigiéndose a sus más grandes desafíos: su necesidad de fortalecer sus instituciones públicas $\left(127^{\circ}\right)$ mediante el aumento de la eficiencia del gobierno, la lucha contra la corrupción $\left(103^{\circ}\right)$, y la mejora de la infraestructura $\left(88^{\circ}\right)^{\prime \prime}$. (El énfasis es propio).

Las cifras descritas y su análisis nos muestran un contexto conocido. Aquel en el que los proyectos de inversión se enfrentan a los problemas asentados como parte de la

3 Minería en Cifras. Sociedad de Minería y Petróleo. Marzo, 2014. http://www.snmpe.org.pe/informes-y-publicaciones-snmpe/nuestros-sectores-encifras/mineria-en-cifras-2014.html

$4 \quad$ The Global Competitiveness Index 2014-2015. En: World Economic Forum, p. 51,322-323. 
política estatal, siendo estos la carencia de instituciones públicas eficientes, corrupción y un decrecimiento en la libertad de empresa. Al respecto, Richard Martín Tirado afirma lo siguiente:

“Es indudable que el régimen legal aplicable a las iniciativas privadas en nuestro ordenamiento jurídico, ha evidenciado una notable evolución de la década de los noventa en adelante, lo cual constituye un aspecto favorable en las tareas de promoción de la inversión privada. No obstante ello, los procedimientos para la tramitación de las iniciativas privadas son muy engorrosos, motivo por el cual es conveniente simplificar estos procedimientos a fin de promover la presentación de iniciativas privadas innovadoras.

\section{$[\ldots]$}

Existe en nuestro país, una excesiva intromisión política en los asuntos de promoción de la inversión privada que pueden desincentivas la presentación de iniciativas privadas [... $]^{5 "}$. (El énfasis es propio).

Así pues, los proyectos de inversión se enfrentan a procedimientos administrativos engorrosos los cuales en lugar de abrir paso a la inversión la dificultan. Si el Estado quiere impulsar el desarrollo de empresas, debe orientar su actuar y el de la Administración Pública a la calidad y eficiencia en cumplimiento de su función de regulación y control. Al respecto, Mir Piugpelat, al hablar de las características de las funciones del Estado y su poder público indica lo siguiente:

"Las funciones de regulación y de control reconocidas actualmente al Estado, a los poderes públicos, presentan al menos cinco grandes novedades que las distinguen de su configuración tradicional.

$[\ldots]$

La segunda es que ambas funcionen quedan ahora también sometidas a los principios de calidad y eficiencia. Ello significa que las normas y los instrumentos de control de su cumplimiento atribuidos a la Administración deben cumplir determinados niveles de calidad y - al mismo tiempo- ser lo menos costosos posible tanto para el erario público [...] como, sobre todo, para las empresas y restos de particulares. Han proliferados así, en toda Europa, importantes iniciativas de simplificación normativa y procedimental, aumentando la claridad de las normas suprimiendo procedimientos autorizatorios duplicados, trámites innecesarios, reduciendo los plazos de resolución administrativa y la documentación a presentar por los interesados, generalizando el silencio positivo, sustituyendo la autorización

5 Martín, Richard, "Balances y Perspectiva del Régimen de las Iniciativas Privadas en el Perú". En: Revista de Circulo Administrativo, 2007, p.351. 
administrativa por la mera comunicación previa, etcétera" ${ }^{6}$. (El énfasis es propio).

Por lo expuesto, es importante que se sustituya el binomio burocracia-corrupción por uno que tenga como principal propósito impulsar las libertades de mercado y el fortalecimiento de la institucionalidad, lo cual no significa mayor cantidad de procedimientos, sino la búsqueda de una simplificación administrativa que permita reducir costos tanto a la Administración como al administrado e incentive la inversión, y con ella el desarrollo del país.

En este contexto, importa analizar el cambio de escenario que se viene viviendo en el sector minero-ambiental desde el 2013. A partir de este año, es claro que se está desarrollando un marco legal que fomenta el régimen de promoción de la inversión privada por la vía de facilitar los procedimientos administrativos a través de la reducción de plazos y la uniformización y flexibilización de criterios por parte de la autoridad administrativa.

Por lo expuesto, el propósito de este artículo es destacar y dar a conocer, dos iniciativas vinculadas con la regulación minera y ambiental; estas son las siguientes: el informe técnico sustentatorio o "ITS" y el informe técnico minero o "ITM". El primero, regulado por el Decreto Supremo 054-2013-PCM entre otras normas, permite modificar componentes auxiliares 0 hacer ampliaciones en proyectos de inversión con certificación ambiental aprobada que tengan impacto ambiental no significativo. El segundo, regulado por Decreto Supremo 001-2015-EM permite modificar los componentes auxiliares o hacer ampliaciones en la concesión de beneficio aprobada, entre otras características. Es decir, ambos instrumentos (uno para el tema ambiental y otro para el tema minero) responden al mismo supuesto de hecho, la necesidad de realizar modificaciones al proyecto de inversión minero.

Para estos efectos se analizará lo siguiente: (i) el escenario previo a la vigencia del ITS y el ITM, (ii) el escenario actual, los cambios generados y su problemática; y finalmente, (iii) se analizará el contexto en el que nos encontramos y lo que podría mejorarse.

\section{Escenario previo: modificación de los estudios de impacto ambiental}

Como ocurre con la mayoría de proyectos de inversión, los proyectos mineros requieren el inicio de diversos procedimientos administrativos para la obtención de innumerables permisos y autorizaciones, cada uno más complejo que el otro. En este escenario y de acuerdo a lo dispuesto por la Ley del Sistema Nacional de Evaluación de

6 Piugpelat, Mig, Globalización, Estado y Derecho. Las transformaciones recientes del Derecho Administrativo. Editorial Civitas. 2004, p. 119. 
Impacto Ambiental - Ley 274467 (que a su vez, se inspira en el artículo 67 de la Constitución ${ }^{8}$ ), los proyectos de inversión pública, privada o de capital mixto, que impliquen actividades, construcciones, obras y otras actividades comerciales y de servicios que puedan causar impactos ambientales negativos significativos, requieren contar con una certificación ambiental previa.

En ese sentido, ninguna autoridad nacional, sectorial, regional o local puede aprobar, autorizar, permitir, conceder o habilitar las actividades señaladas en el párrafo anterior si no cuentan previamente con una certificación ambiental.

Como se puede apreciar, las normas ambientales en general se han ocupado de consagrar que nada que pueda generar impactos ambientales significativos se pueda llevar a cabo sin la correspondiente certificación ambiental. Así pues, se ha identificado la conducta prohibida sin pensar en lo que sí estaba o debería estar permitido para favorecer la libertad y la creación de riqueza. Tan es así que son pocas las regulaciones ambientales sectoriales que se han ocupado en detalle de identificar qué actividades 0 modificaciones a los proyectos podrían efectuarse sin que esto implique modificar la certificación o aprobación ambiental respectiva.

Sobre el particular el artículo 48 del Reglamento de la Ley del Sistema Nacional de Evaluación de Impacto Ambiental, aprobado por Decreto Supremo 019-2009-MINAM establece lo siguiente:

"Artículo 48.- El ElA debe ser elaborado sobre la base del proyecto de inversión diseñado a nivel de factibilidad. La Autoridad Competente no admitirá a evaluación un EIA si no se cumple esta condición".

De acuerdo con la normativa citada, un estudio de impacto ambiental se debe elaborar a un nivel de factibilidad, lo cual implica que éste se prepare y apruebe no solo antes de empezar la construcción y operación del proyecto sino, además, antes de siquiera definir el detalle final de éste. Es decir, primero se trata de determinar su viabilidad técnica, económica y ambiental para luego, con la ejecución del proyecto, preparar la

$7 \quad$ Artículo 3.- Obligatoriedad de la certificación ambiental

No podrá iniciarse la ejecución de proyectos ni actividades de servicios y comercio referidos en el artículo 2 y ninguna autoridad nacional, sectorial, regional o local podrá aprobarlas, autorizarlas, permitirlas, concederlas o habilitarlas si no cuentan previamente con la certificación ambiental contenida en la Resolución expedida por la respectiva autoridad competente.

Artículo 67.- El Estado determina la política nacional del ambiente. Promueve el uso sostenible de sus recursos naturales. 
ingeniería detallada del mismo lo cual implica una inversión en tiempo y dinero significativa ${ }^{9}$.

Siendo ello así, es inevitable que durante las actividades de diseño final, de detalle o incluso de construcción y posterior operación del proyecto, surjan necesidades que obliguen al titular minero a modificar, incluir y/o suprimir diversos componentes, tales como plataformas, accesos, tuberías, campamentos, instalaciones, entre otros. Para esto los estudios ambientales evalúan un área de influencia directa y un área de influencia indirecta lo cual permite técnicamente pequeñas variaciones al proyecto original.

Sin embargo, la normativa minero-ambiental, como estaba estructurada, no permitía que el titular de la actividad minera tenga la libertad de hacer dichas pequeñas variaciones pues para evitar arriesgarse a una sanción, requería iniciar el largo y costoso proceso de modificar su estudio de impacto ambiental lo cual, en definitiva, implicaba que el proyecto se paralice por un periodo aproximado de un (1) año o más.

Ahora bien, lo cierto es que los cambios o modificaciones son naturales, toda vez que es imposible determinar todos los alcances de todas las actividades, sin que en el camino se pueda detectar que existan mejores alternativas o que la realidad práctica de un determinado proyecto haga recomendable hacer ajustes al mismo.

Esto último permite verificar que al anterior marco regulatorio minero-ambiental, así como a sus procedimientos, les faltaba una cuota importante de flexibilidad, para permitir cambios y modificaciones de los instrumentos de gestión ambiental sin tener que pasar por el procedimiento de modificación referido anteriormente lo cual no significa eliminar la evaluación de los cambios, sino la posibilidad de permitir una mayor libertad y eficiencia dependiendo del caso.

Tras la promulgación del Decreto Supremo 054-2013-PCM, y otras disposiciones que han enriquecido, complementado y desarrollado el contenido del mencionado decreto, el escenario descrito ha cambiado. Por ello, procedemos a describirlo.

\section{Informe técnico sustentatorio}

Desde la promulgación del Decreto Supremo 054-2013-PCM hasta el reciente Reglamento de Protección y Gestión Ambiental para las Actividades de Exploración, Beneficio, Labor General, Transporte y Almacenamiento Minero, aprobado por Decreto

$9 \quad$ Si bien el análisis de las características para la elaboración de un estudio de impacto ambiental no son materia de estudio en el presente artículo cabe afirmar que el procedimiento para la elaboración de dichos ha variado a razón del Decreto Supremo 040-2014-EM. 
Supremo 040-2014-EM ${ }^{10}$ (en adelante, el "Reglamento"), las normas en materia minero-ambiental han buscado impulsar los proyectos de inversión, a través de la disminución de plazos y simplificación de procedimientos administrativos. En efecto, el artículo 4 del mencionado Decreto Supremo buscó simplificar el procedimiento de modificación de un instrumento de gestión ambiental de la siguiente manera:

"Artículo 4.- Disposiciones ambientales para los proyectos de inversión

En los casos en que sea necesario modificar componentes auxiliares ${ }^{11} 0$ hacer ampliaciones en proyectos de inversión con certificación ambiental aprobada que tienen impacto ambiental no significativo 0 se pretendan hacer mejoras tecnológicas en las operaciones, no se requerirá un procedimiento de modificación del instrumento de gestión ambiental. El titular del Proyecto está obligado a hacer un informe técnico sustentando estar en dichos supuestos ante la autoridad sectorial ambiental competente antes de su implementación. Dicha autoridad emitirá su conformidad en el plazo máximo de 15 días hábiles. En caso que la actividad propuesta modifique considerablemente aspectos tales como, la magnitud o duración de los impactos ambientales del proyecto 0 de las medidas de mitigación 0 recuperación aprobadas, dichas modificaciones se deberán evaluar a través del procedimiento de modificación". (El énfasis es propio).

Como bien se ha descrito anteriormente, antes de la promulgación del mencionado Decreto Supremo, la legislación minero ambiental, como estaba estructurada, no permitía que el titular de la actividad minera tuviera la libertad de efectuar cambios sin modificar el instrumento de gestión ambiental con el que contaba. Esta modificación, en definitiva, implica que el proyecto se paralice y; con ello, se detenga el flujo de capital, generando costos administrativos y logísticos traducidos en pérdidas.

Ahora, al amparo del artículo citado, ciertas modificaciones son permitidas. Por ejemplo, (i) modificaciones de componentes auxiliares, (ii) ampliaciones en proyectos de inversión o (iii) mejoras tecnológicas sobre proyectos ${ }^{12}$ que ya cuenten con una

10 La mencionada norma entró en vigencia tras la aprobación de los términos de referencia por la Resolución Ministerial 116-2015-MEM/DM.

11 Respecto a los componentes auxiliares, el Reglamento de Protección y Gestión Ambiental para las Actividades de Explotación, Beneficio, Labor General, Transporte y Almacenamiento Minero aprobado por Decreto Supremo 040-2014-EM describe a los componentes mineros auxiliares como "aquellos componentes secundarios o de servicio que complementan los objetivos o funciones de los componentes principales permitiendo concluir con la actividad de explotación para obtener y colocar los productos mineros en la industria. Son considerados como tales: ductos (mineroductos y acueductos), campamentos, almacenes, polvorines, grifos, canales de coronación, carreteras o trochas, líneas de transmisión eléctrica [...]".

12 En base a la Segunda Disposición Complementaria Final del Decreto Supremo 060-2013PCM, se debe entender como proyectos de inversión a los proyectos de inversión privados y públicos en general. 
certificación ambiental aprobada en la medida que el impacto ambiental sea no significativo. En estos supuestos, no se requerirá llevar a cabo el procedimiento de modificación del instrumento de gestión ambiental sino simplemente presentar un ITS a la autoridad ambiental competente para su aprobación.

Al respecto, cabe preguntarse lo siguiente: ¿qué se debe entender por "ampliación en proyectos"? o ¿qué comprende una "mejora tecnológica"? En un primer momento se intentó resolver estas interrogantes con la Resolución Ministerial 310-2013-MEM-DM, que aprobó los criterios que regularían las modificaciones de los componentes mineros y/o ampliaciones y mejoras tecnológicas de las unidades mineras de proyectos de exploración y explotación con impactos ambientales no significativos que cuenten con certificación ambiental; así como también, la estructura mínima del ITS. Sin embargo, la mencionada norma no contemplaba muchos supuestos que podían ser interpretados también como modificaciones con impactos negativos no significativos. En ese escenario, el 27 de febrero de 2014, entró en vigencia la Resolución Ministerial 120 2014-MEM-DM. Esta Resolución, vigente a la fecha, actualizó los criterios recogidos en la primera Resolución Ministerial indicada.

En la mencionada Resolución se buscó aprobar disposiciones especiales para la ejecución de procedimientos administrativos, con el fin que los profesionales de la Dirección General de Asuntos Ambientales Mineros - DGAAM del Ministerio de Energía y Minas a cargo de la revisión y evaluación de los ITS, de las modificaciones o ampliaciones de los proyectos mineros o mejoras tecnológicas en las operaciones, en las etapas de exploración, explotación o cierre, puedan verificar y/o determinar que los impactos ambientales identificados califiquen como impactos negativos no significativos.

Estos criterios técnicos consideran parámetros cualitativos y cuantitativos para las modificaciones, ampliaciones y/o mejoras tecnológicas que se plantean con el objeto de que sean fácilmente medibles por parte del titular y por la DGAAM. Comprenden también las reducciones de extensiones de componentes que, por sí solos, implican la reducción de impactos negativos 0 adiciones de componentes que también signifiquen impactos y riesgos negativos pocos significativos.

Cabe resaltar que los criterios expuestos en la norma descrita no deben entenderse como un listado cerrado de las modificaciones que se pueden llevar a cabo; toda vez que, como bien se ha señalado, la regla de la cual se derivan los mencionados criterios implica que se podrá presentar un ITS respecto de cualquier modificación que cause impacto negativo no significativo. Esta idea está resaltada en el artículo 131 del Reglamento en el cual se establece lo siguiente:

“Artículo 131.- Excepciones al trámite de modificación del estudio ambiental

Sin perjuicio de la responsabilidad ambiental del titular de la actividad minera por los impactos que pudiera genera su actividad, conforme a lo 
señalado en el artículo 16 y a lo indicado en el artículo anterior, el titular queda exceptuado de la obligación de tramitar la modificación del estudio ambiental, cuando la modificación o ampliación de actividades propuestas, -valoradas en conjunto con la operación existente- y comparadas con el estudio ambiental inicial y las modificaciones subsiguientes aprobadas, se ubiquen dentro de los límites del área del proyecto establecida en el estudio ambiental previamente aprobado y generen un impacto 0 riesgo ambiental no significativo.

En tal sentido, se aceptarán excepciones como las siguientes:

\section{$[\ldots]$}

h) Otras modificaciones que resulten justificadas que representen un similar o menor impacto ambiental y aquellas que deriven de mandatos $y$ recomendaciones dispuestas por la autoridad fiscalizadora.

La autoridad ambiental competente, evalúa previamente las propuestas de excepción que los titulares mineros presenten, de conformidad con el artículo 4 del Decreto Supremo 054-2013-PCM, la Resolución Ministerial 120-2014-MEM-DM y demás normas modificatorias". (El énfasis es propio).

Por otro lado, el artículo 132 indica que:

“Artículo 132.- De la presentación del Informe Técnico Sustentatorio

En los casos considerados en el artículo anterior, el titular de la actividad minera debe previamente al inicio de las actividades y obras involucradas, presentar un informe técnico sustentatorio [...]". (El énfasis es propio).

En ese sentido, mientras se cumpla con realizar modificaciones con un impacto negativo no significativo (respaldado en un estudio técnico), independientemente que los mencionados cambios se encuentren o no en las normas citadas, el instrumento apropiado a presentar ante la autoridad ambiental competente previo desarrollo de las modificaciones será ITS.

Así pues, el ITS se muestra como una alternativa que atiende la dinámica del negocio minero, entendiendo que un proyecto no es predecible y que siempre está sujeto a cambios. En comparación con el procedimiento de modificación de instrumento de gestión ambiental, éste se presenta como una alternativa que genera incentivos para que el titular de un proyecto minero busque optimizarlo, reduciendo los costos de su actividad y a su vez disminuyendo su impacto negativo sobre el ambiente, pues la paralización de actividades para la aprobación del mencionado instrumento no será de un (1) año pero de algunos meses. En todo caso y sin perjuicio de su impacto positivo, cabe cuestionar si el ITS resulta el medio más idóneo para facilitar modificaciones poco significativas a los proyectos 
Como bien se indicó anteriormente, la Administración Pública tiene la función de garantizar la libre competencia, y favorecer el desarrollo del mercado ${ }^{13}$. En este escenario, el ITS se convierte en un trámite innecesario cuando la modificación que se desarrolle no represente un impacto significativo o cuando se trate simplemente de una optimización de un proyecto. Por ello, lo idóneo, al buscar la simplificación administrativa, es sustituir la autorización administrativa por la comunicación previa bajo responsabilidad del titular, responsabilidad que ya se encuentra regulada en las normas ambientales citadas.

A pesar que el ITS no alcanza una verdadera simplificación administrativa, consideramos que se trata de una iniciativa valiosa y respetable. Sin embargo, haría falta evaluar la forma en la cual la autoridad ambiental competente actuará frente a las eventuales modificaciones que se realicen de los proyectos de inversión. Finalmente, será dicha autoridad la que determine si la modificación generará o no algún impacto negativo no significativo ${ }^{14}$ y con ello si corresponde que el titular del proyecto de inversión minera deba realizar un ITS o una modificación a su instrumento de gestión ambiental. En todo caso, la reforma constituye un primer paso hacia la eficiencia normativa.

\section{I nforme técnico minero: un paso más hacia la eficiencia normativa}

Al igual que en materia ambiental, se advirtió la necesidad de un ITS en tanto se requiera cambiar los componentes del instrumento de gestión ambiental mientras tales modificaciones no representen un impacto negativo significativo, de cara al aspecto minero pues, que el titular del proyecto de inversión busque llevar a cabo los mencionados cambios también implicaba modificar la concesión de beneficio otorgada.

Bajo este escenario, el 5 de enero de 2015, mediante Decreto Supremo 001-2015-EM, se aprobaron disposiciones que facilitan los procedimientos mineros con el fin de impulsar los proyectos de inversión. Así pues, se reguló la presentación del Informe Técnico Minero ("ITM") de forma análoga al ITS, a efectos de tener dos procedimientos simplificados que permitan llevar a cabo un mismo supuesto de hecho: modificar componentes auxiliares o hacer ampliaciones en proyecto de inversión con certificación ambiental aprobada que tengan un impacto negativo mínimo.

13 Tal como lo dispone el Régimen Económico contemplado en la Constitución Política del Perú.

14 Cabe resaltar nuevamente que, si la autoridad competente determina que las modificaciones que el titular minero desea realizar traen consigo impactos negativos significativos, entonces, será necesario modificar el instrumento de gestión ambiental. 
En esta línea, el artículo 4 de la mencionada norma ${ }^{15}$ permite que, a través del ITM ya no se tenga que iniciar un procedimiento de modificación de concesión de beneficio siempre que se busque modificar o ampliar lo siguiente:

i. La capacidad instalada o la instalación de componentes que impliquen nuevas áreas, siempre que éstas se encuentren dentro del área aprobada en el instrumento ambiental;

ii. La capacidad instalada para instalaciones adicionales y/o mejora tecnológica de procesos sin ampliación de área;

iii. Instalaciones adicionales sin modificación de la capacidad instalada y sin ampliación de área.

Así, en caso los aspectos a modificar correspondan a los señalados en el párrafo anterior, se podría hacer uso del ITM evitando modificar la concesión de beneficio y sin necesidad de llevar a cabo el procedimiento regulado en el Anexo A, del Decreto Supremo 020-2012-EM, que modificó el Reglamento de Procedimientos Mineros (Decreto Supremo 018-92).

Cabe precisar que, para poder modificar los aspectos ya mencionados, es necesario contar con un ITS aprobado previamente por la autoridad ambiental competente. De este modo, se entiende que ambas instrumentos técnicos (el ITM y el ITS) son aplicables a circunstancias iguales (modificaciones que no significan impactos negativos); sin embargo, el primero está referido al aspecto minero de la concesión, mientras el segundo se refiere al aspecto ambiental.

En todo caso, esta norma no está exenta de incongruencias. Por ejemplo, establece que los documentos a presentar para la obtención de ITM son los siguientes:

- Número de Resolución Directoral de la autoridad ambiental que conformidad del Informe Técnico Sustentatorio.

- Memoria descriptiva según formato electrónico aprobado por Resolución Ministerial.

15 Artículo 4.- Disposiciones para los casos de presentación de Informe Técnico Minero 4.1. En los casos en que sea necesario modificar o ampliar: (i) la capacidad instalada o la instalación de componentes que impliquen nuevas áreas, siempre que éstas se encuentren dentro del área aprobada en el instrumento ambiental; (ii) la capacidad instalada para instalaciones adicionales $\mathrm{y} / 0$ mejora tecnológica de procesos sin ampliación de área; (iii) instalaciones adicionales sin modificación de la capacidad instalada y sin ampliación de área; no se requerirá iniciar un procedimiento de modificación de concesión de beneficio, si cuenta con la conformidad del Informe Técnico Sustentatorio, otorgada por la autoridad ambiental, conforme al artículo 4 del Decreto Supremo 054-2013-PCM [...]". 
- Acreditar la titularidad o autorización del uso de (los) terreno(s) superficiales(es).

- Copia simple de la licencia de uso de agua, o balance de Agua de ser el caso.

Sobre la acreditación de la titularidad o autorización de terrenos superficiales se distingue entre terrenos inscritos y no inscritos. Además, se establece una diferencia frente a los requisitos necesarios a cumplir respecto de terrenos de Comunidades Campesinas. En el caso de los terrenos de las comunidades se indica que será necesario presentar, entre otros documentos, copia legalizada del Acta de la Junta Directiva de la Comunidad Campesina ${ }^{16}$.

Al respecto, importa tener presente que, de acuerdo al artículo 16 de la Ley de Comunidades Campesinas, Ley $24656^{17}$, son órganos de gobierno de la comunidad los siguientes:

- $\quad$ La Asamblea General,

- $\quad$ La Directiva Comunal; y

- $\quad$ Los Comités Especializados por actividad y por Anexo.

Es claro entonces que no existe órgano alguno denominado "Junta Directiva de la Comunidad Campesina", pero sí existe una Directiva Comunal. En todo caso, aún interpretando que el legislador quiso decir "Directiva Comunal", este órgano no tiene facultades para autorizar el uso del terreno superficial de la Comunidad Campesina ya que esta competencia, recae en la Asamblea General. En esta línea, el artículo 11 de la Ley de la Inversión Privada en el Desarrollo de las Actividades Económicas en las

16 Artículo 3.- Simplificación para el procedimiento de Concesión de Beneficio regulado por el Reglamento de Procedimientos Mineros

[...]

c. Para terrenos superficiales que se encuentren inscritos a nombre de Comunidades Campesinas: [...] iii. Copia legalizada del Acta de la Junta Directiva de la Comunidad Campesina que otorga la autorización del uso del terreno superficial a favor del solicitante, así como la designación de los representantes de la misma, autorizados para suscribir el acto de disposición correspondiente a favor del solicitante.

[...]

d. Para terrenos superficiales que se encuentren en posesión de Comunidades Campesinas pero que no se encuentren inscritos a su favor: [...] iv. Copia Legalizada del Acta de la Junta Directiva de la Comunidad Campesina que otorga la autorización del uso del terreno superficial a favor del solicitante, así como la designación de los representantes de la misma, autorizados para suscribir el acto de disposición correspondiente, a favor del solicitante.

17 Artículo 16.- Son órganos de gobierno de la Comunidad Campesina:

La Asamblea General;

La Directiva Comunal; y

Los Comités Especializados por actividad y Anexo.

FORSETI

Número 1

$\supset 015$ 
Tierras del Territorio Nacional y de las Comunidades Campesinas y Nativas, Ley 26505, establece lo siguiente:

"Artículo 11.- Para disponer, gravar, arrendar o ejercer cualquier otro acto sobre las tierras comunales de la Sierra o Selva, se requerirá del Acuerdo de la Asamblea General con el voto conforme de no menos de los dos tercios de todos los miembros de la Comunidad". (El énfasis es propio).

Por lo expuesto, el requisito solicitado descansa sobre una contradicción. Si bien cumplirlo de acuerdo con lo dispuesto en el artículo 3 del Decreto Supremo 001-2015EM podría significar obtener válidamente el ITM, en base a una interpretación sistemática con las normas citadas, siendo esto lo adecuado y conforme a ley, es obtener la aprobación de la Asamblea General para el uso de las tierras comunales. Esto sumado al hecho que, las leyes que recogen las competencias de la Asamblea General de la Comunidad Campesina tienen un rango jerárquico superior al Decreto Supremo en el que sustenta el ITM.

En todo caso, si es que existe este tipo de confusiones en la norma, y el resolverla implica remitirse a distintos cuerpos normativos, todos ellos abiertos a interpretación, solo queda imaginarnos los problemas que se generarán al momento que la autoridad competente evalúe el cumplimiento de los requisitos de las modificaciones, de cara a la aprobación del ITM. No olvidemos que su obtención es requisito indispensable para llevar a cabo las modificaciones o ampliaciones requeridas y que, hasta obtenerlo, las actividades de explotación se encontrarían paralizadas.

\section{V. ¿Qué queda por hacer? : Abriendo paso a la regulación positiva}

Luego de haber explicado de forma muy resumida la situación actual del modelo regulatorio en materia medio ambiental y minera respecto a las nuevas herramientas legales existentes para "modificar" instrumentos ambientales o las concesiones de beneficio, consideramos que la aprobación de los instrumentos legales descritos, es decir, el ITS y el ITM, son el primer paso para lograr un modelo más flexible y dinámico en donde se reconozca una "regulación positiva"18.

La regulación positiva pasa por el reconocimiento como principio administrativo del principio jurídico y constitucional de que "lo que no está prohibido está permitido" y está relacionada con otros principios generales del Derecho, como el de libre iniciativa privada, la subsidiariedad regulatoria y el de "favor libertatis" o el de la interpretación más preferente hacia la libertad en lugar que las restricciones en materia administrativa.

Las características del mencionado principio pueden resumirse en lo siguiente:

18 Véase, "Simplificación Administrativa y "Regulación Positiva" en la normativa ambiental y minera". En: Revista Derecho \& Sociedad, N. 42, 2014, p. 279-287. 
- Darle a la administración la tranquilidad de que sus actos no serán cuestionados posteriormente por aceptar expresamente, desde la propia ley, que no cabe el otorgamiento de un permiso cuando la norma no lo exige

- Analizar la nueva regulación identificando la conducta prohibida pero además qué conductas se entienden permitidas o aquellas a las que la norma que se pretende expedir no alcanza. Es decir, objetivar adecuadamente el campo de aplicación de la norma ${ }^{19}$. Asimismo, requiere que al efectuar dicho análisis, el legislador realice un análisis costo-beneficio, identificando el efecto real de la nueva regulación, prohibición o procedimiento. Para ello es fundamental trabajar exposiciones de motivos y guías metodológicas que deben ser aprobadas de forma conjunta con las nuevas regulaciones.

En conjunto con lo anterior, es necesario contar con una regulación que promueva la simplificación administrativa. En este sentido, se podría trabajar en promover la comunicación y coordinación entre todas las autoridades administrativas que tengan alguna incidencia en los permisos, autorizaciones y licencias requeridas para la operación de un proyecto minero, y así se pueda elaborar un documento consolidado conjunto que permita conocer de antemano la mayoría de permisos, autorizaciones y licencias que se van a requerir para desarrollar un proyecto.

En este marco, el ITS y el ITM responden a este marco de regulación positiva al brindar mayor libertad al administrado para incluir, modificar y/o sustituir componentes que inicialmente no estuvieron contemplados, al menos expresamente, para el eficiente desenvolvimiento del proyecto de inversión minero, pero que en la práctica requieren ser modificados o ampliados por las razones anteriormente expuestas. Sin embargo, existe la posibilidad de simplificar el procedimiento aún más con la incorporación de la figura de las "Declaraciones Juradas", en reemplazo de tales instrumentos.

La figura de la Declaración Jurada, como medio sustitutorio de ciertos títulos habilitantes, es una figura que fue incorporada en la Ley de Simplificación Administrativa $^{20}$, pero que ha perdido ciertamente mucho espacio en nuestro ordenamiento. Conviene tener presente que esta figura, ya ha sido empleada y comprobada en legislación foránea. Así, por ejemplo, en el derecho italiano se habla de la "declaración de inicio de actividades". Al respecto, Núñez Lozano, señala lo siguiente:

“El rasgo más significativo del régimen de la declaración de inicio de actividad es el de que con ella se prescinde, no ya del acto escrito (que es

19 Como lo hace por ejemplo la Ley de Contrataciones del Estado, la cual señala expresamente a cuáles contratos si aplica, y a cuáles no. 
lo que sucede con las diferentes modalidades de silencio administrativo que contempla la propia Ley 241/1990), sino del acto en sí, la autorización o del acto administrativo mismo [...] Señaladamente, la declaración de inicio de la actividad en el Derecho italiano sustituye a la decisión de la Administración, lo que a juicio de la doctrina, justifique que no se trate de un supuesto de inactividad de la Administración"21.

Del mismo modo, esta figura también ha sido regulada en España, con las figuras "comunicación previa" o "declaración responsable", las mismas que se detallan a continuación:

"La comunicación previa es descrita, por el artículo 71 bis de la Ley 30/1992, como aquel documento mediante el que los interesados ponen en conocimiento de la Administración Pública competente sus datos identificativos y demás requisitos exigibles para el ejercicio de un derecho o el inicio de una actividad, de acuerdo con lo establecido en el artículo 70.1.

Se recoge como declaración responsable el mismo precepto: el documento suscrito por un interesado en el que manifiesta, bajo su responsabilidad, que cumple con los requisitos establecidos en la normativa vigente para acceder al reconocimiento de un derecho o facultad para su ejercicio, que dispone de la documentación que así lo acredita y que se compromete a mantener su cumplimiento mediante un periodo de tiempo inherente a dicho reconocimiento o ejercicio.

La normativa califica a ambas figuras, de entrada, de "documentos" Documentos que deben suscribir las personas interesadas en ejercitar un derecho, facultad o desempeñar una actividad"22.

De acuerdo a lo anterior, esta posibilidad podría utilizarse en una serie de actividades y permisos, que por su propia naturaleza, no requieran una intensiva participación del Estado, para aprobarlas. Un claro ejemplo se da en el campo de los instrumentos de gestión ambiental, en donde la figura de las Declaraciones Juradas puede convertirse en una solución frente al exceso de regulación que existe actualmente.

Finalmente, no podemos dejar de mencionar la reciente entrada en vigencia del Reglamento de Protección y Gestión Ambiental para las Actividades de Exploración, Beneficio, Labor General, Transporte y Almacenamiento Minero, aprobado por Decreto Supremo 040-2014-EM, debido a que su aprobación es otro hito importante hacia la evolución de nuestra legislación y es relevante de cara al desarrollo de la actividad minera. La aprobación de esta norma representa una mejora en la normativa minero-

21 Nuñez Lozano, María del Carmen, Las actividades comunicadas a la Administración. Madrid, Marcial Pons, 2001, p. 37-40.

22 Rodríguez Font, Mariola, "Técnicas de control en la Transposición de la Directiva de Servicios: Comunicación previa y declaración responsable". En: La Termita Bolkestein, Navarra, Aranzadi, p. 82. 
ambiental, al adecuarla a la Ley del Sistema Nacional de Evaluación de Impacto Ambiental.

La finalidad del Reglamento, aplicable a la mediana y gran minería, es asegurar que las actividades mineras que se realicen en el territorio nacional se desarrollen en respeto del derecho constitucional al disfrute de un "ambiente equilibrado y adecuado al desarrollo de la vida". Sin embargo, esto no debe significar una obstaculización al ejercicio de los derechos a la libre iniciativa privada y al aprovechamiento sostenible de los recursos naturales. De este modo, a través del ordenamiento de procedimientos, la simplificación de los mismos y la reducción de plazos el Estado estaría cumpliendo su labor de fomento a la actividad privada y el desarrollo de la riqueza, consagrado en el artículo 58 de nuestra Constitución, con miras a lograr una verdadera regulación positiva.

\section{Conclusión}

Por lo expuesto, para lograr un mayor impulso de los proyectos de inversión se debe aumentar la claridad de las normas suprimiendo procedimientos y trámites innecesarios, reduciendo plazos y sustituyendo la autorización administrativa por la comunicación previa

En este marco, el ITS y el ITM responden de alguna manera a estas necesidades permitiéndole al administrado incluir, modificar $\mathrm{y} / 0$ sustituir componentes que inicialmente no estuvieron expresamente contemplados en el diseño original del proyecto, sin embargo, para muchos casos estos instrumentos no son suficientes

En este contexto, la Declaración Jurada resulta ser una propuesta válida, eficiente y menos costosa frente a las modificaciones de un proyecto de inversión y de su instrumento de gestión ambiental. Por ello, consideramos que sería recomendable elaborar un listado de actividades permitidas, es decir actividades que de por sí, no debieran generar un impacto significativo en el ambiente. Para realizarlas sólo se debe presentar una Declaración Jurada, en donde se adjunte un sustento técnico de las modificaciones o cambios a incluir. Dichas comunicaciones, estarían sujetas a un estricto control por parte de la autoridad, asumiendo el titular minero, la responsabilidad por las mismas.

En todo caso, la idea detrás del ITS, ITM y de la Declaración Jurada, es brindar al administrado un régimen de verdadera simplificación administrativa, determinando adecuadamente las zonas de aplicación de lo prohibido, pero también precisando y justificando el ámbito de las zonas permitidas para así generar más transparencia y predictibilidad para la inversión privada. Esto último acompañado de nuevas tendencias y técnicas que otorguen la seguridad necesaria para que los administrados y la propia administración colaboren en el desarrollo sostenible del país en materia minera y ambiental. 